\title{
As relações políticas entre romanos e bárbaros no Mediterrâneo tardo-antigo
}

\author{
The political relations between Romans and barbarians in the Mediterranean \\ in Late Antiquity
}

\author{
Renato Viana Boy \\ Universidade Federal da Fronteira Sul (UFFS), Chapecó, SC, Brasil
}

\begin{abstract}
RESUMO: A tradição historiográfica marca o ano 476 como o fim do Império Romano no Ocidente, ficando a manutenção das estruturas imperiais, a partir de então, restrita aos territórios orientais de cultura grega. Uma questão a se pensar é: quais tipos de relaçóes políticas poderiam ser observados entre o império oriental grego e o ocidente "bárbaro" no Mediterrâneo a partir de fins do século V e início do VI? Para analisarmos especificamente sobre o período que se sucede à deposição de Romulus Augustulus na Itália, utilizar-nos-emos de dois historiadores do século VI que descreveram sobre as relações políticas entre Constantinopla e a Itália neste período, Jordanes e Procópio de Cesareia. O objetivo aqui será compreender como, a partir das narrativas destes dois historiadores, podemos repensar algumas das relaçóes e disputas pelo exercício do poder e da autoridade política no mundo Mediterrânico tardo-antigo.
\end{abstract}

PALAVRAS-CHAVE: Mediterrâneo. Jordanes. Procópio de Cesareia.

ABSTRACT: The historiographical tradition marks the year 476 as the end of the Roman Empire in the West, being the maintenance of the imperial structures, from then on, restricted to the Eastern territories of Greek culture. One question to think about is: what kind of political relations could be observed between the Eastern Greek Empire and the western 'barbarian' in the Mediterranean from the end of the fifth and early sixth centuries? In order to analyze specifically the period following the deposition of Romulus Augustulus in Italy, we will work with two historians of the sixth-century, who described the political relations between Constantinople and Italy in this period, Jordanes and Procopius of Caesarea. The aim will be to understand how, from the narratives of these two historians, we can rethink some of the relations and disputes over the power and political authority in the Mediterranean world in Late Antiquity.

KEYWORDS: Mediterranean. Jordanes. Procopius of Caesarea.

\footnotetext{
* Professor da Universidade Federal da Fronteira Sul (UFFS), Campus Chapecó, SC, Brasil. Doutor em História Social pela Universidade de São Paulo (USP). E-mail: renatoboymedieval@gmail.com http://orcid.org/0000-0001-5500-6256
} 


\section{Introdução}

Um dos primeiros passos para a elaboração de um projeto de pesquisa em História, que acompanha invariavelmente a escolha de um tema, são os recortes que o pesquisador necessariamente tem de fazer. Além da seleção da documentação (seja ela de natureza escrita, pictórica, arquitetônica, arqueológica, ou outra), o historiador deve estabelecer alguns limites ao tema a ser trabalhado, para que a investigação possa ser efetivamente viabilizada. Entre esses recortes, dois fazem-se presentes na grande maioria das pesquisas: o recorte cronológico e o geográfico.

Esta perspectiva de construção de um objeto de pesquisa, com seus recortes, delimitações e objetivos, resultam numa rotulação ou classificação dos temas trabalhados, enquadrando-os em grandes áreas de especialização, definidas a partir do período estudado ou da localização dos eventos ou processos que serão objetos da pesquisa. Assim, esses recortes definem uma temática ou um trabalho de História como pertencente ao período Pré-Histórico, Antigo, Tardo Antigo, Medieval, Moderno ou Contemporâneo. Ou, ainda, de maneira mais específica, mas, nem por isso, menos generalizando, como subperíodos em abordagens mais específicos, como o Alto ou Baixo Império Romano, ou, ainda, a divisão em Alta Idade Média, Idade Média Central ou Baixa Idade Média, ou, ainda, uma localização cronológica que leva em consideração a percepção de alguns processos históricos, como o período feudal, por exemplo. Em termos geográficos, os objetos de estudos também passam por uma classificação que tem por base a localização de seus acontecimentos ou processos, como o romano, franco, bizantino, anglo-saxão, grego, persa, ibérico, entre tantos outros.

O cruzamento destes dois recortes, o cronológico e o geográfico, apresenta ao público leitor um objeto de pesquisa histórica com algumas delimitações que especificam as abordagens, conceitos, referenciais bibliográficos e materiais a serem trabalhados. São estes primeiros recortes que, direta ou indiretamente, com ou sem a intenção do autor, classificam o tema abordado dentro de uma área de especializações dentro dos estudos históricos.

Entretanto, é preciso salientar que tais limites e classificações nos objetos de pesquisa são resultantes das escolhas e do trabalho do historiador. Em outras palavras, nossos documentos, enquanto fontes históricas, não nos são apresentadas, a priori, como resultantes de uma sociedade antiga, tardo-antiga, medieval ou moderna. Neste sentido, vale ressaltar que são os historiadores os responsáveis diretos pela criação, manutenção e fortalecimento das classificaçôes dos espaços e das grandes divisóes temporais que classificam os temas a serem pesquisados.

Neste sentido, cabe uma questão: como lidar metodologicamente com um objeto de pesquisa que não se insere especificamente num dos grandes recortes temporais de classificação da História? Como trabalhar com uma problemática de pesquisa que transcorre entre dois recortes geográficos, cujas fronteiras não significam, necessariamente, uma ausência de relações, conflituosas ou diplomáticas, entre grupos ou sociedades que ocuparam espaços historiograficamente distintos?

A proposta deste artigo é trazer uma discussão que transita entre dois períodos historiográficos distintos, a Antiguidade e o Medievo, e num espaço geográfico não especificamente definido como oriental ou ocidental. Como sabemos, esta não é a primeira experiência de pesquisa que se propõe a analisar relaçôes políticas entre sociedades distintas que não se encaixam exclusivamente no mundo Antigo ou no Medieval, ou que transpassam as fronteiras daquilo que poderíamos chamar, à primeira vista, de Ocidente e Oriente Grego. 
Por outro lado, isso não significa que pretendemos aqui propor um novo modelo de classificação geográfico e temporal para esse tipo de estudo, o que seria por demais pretensioso. Assim, adotaremos aqui uma classificação cronológica e geográfica que, também historiograficamente consagrada, permite transitar entre dois períodos e dois espaços já trabalhados pelos historiadores: o Mediterrâneo Tardo-Antigo. ${ }^{1}$ Dessa forma, o estudo que aqui será apresentado não pretende uma análise polarizada, contrapondo Ocidente e Oriente, cultura latina ou cultura helênica, ou ainda o mundo antigo e o medieval.

Este trabalho pretende repensar a região do Mediterrâneo dos séculos V e VI como um ponto de interseção entre ambientes que, tradicionalmente na historiografia, foram tomados como propostas de estudos distintas: O Império Romano oriental, chamado pela historiografia moderna e contemporânea de Império Bizantino, e as populações góticas na Península Itálica. $\mathrm{O}$ recorte temporal se situa entre a deposição do imperador romano Romulus Augustulus, em 476, e o início das chamadas Guerras de Reconquista de Justiniano, em especial a Guerra Gótica, iniciada por volta de 535, envolvendo as tropas imperiais e os godos, também na Itália.

O material a ser analisado são os textos da Getica (De origine actibusque Getarum), escritas pelo historiador Jordanes e a História das Guerras (do latim, De Bello Gotbico, do grego Uper Twn Polemon), de Procópio de Cesareia. Pensamos que o estudo dos escritos destes historiadores, ambos do século VI, nos permita traçar uma análise parcial das relações existentes entre o governo imperial bizantino e as populações godas no ocidente mediterrânico. Não se trata aqui de verificar exclusivamente relações de conflitos e disputas pelo domínio da autoridade política sobre a Itália a partir dos acontecimentos de 476. Além disso, acreditamos ser possível pensar nas relações entre o poder imperial romano de Constantinopla ${ }^{2}$ e governos godos presentes na Itália neste período como formas de aproximação e disputas muito mais complexas, tendo como objetivo a reorganizar um importante espaço de exercício de autoridade política em construção no Mediterrâneo, após a deposição do último imperador romano no ocidente.

O ponto inicial escolhido para nosso recorte cronológico se justifica por ter sido tomando pela historiografia como um marco didático e historiográfico que divide a Antiguidade da Idade Média. Entretanto, como dito anteriormente, desde a segunda metade do século XX, a partir da publicação de The World of Late Antiquity: A.D. 150-750, de Peter Brown, que a historiografia uma nova abordagem para o processo de transição entre a história Antiga e a Medieval, transformando a compreensão desse processo de transição e transformações da Europa Ociental, ele mesmo, numa temática e num recorte cronológico com problemáticas e perspectivas de estudos próprias: a Antiguidade Tardia. ${ }^{3}$

Portanto, pensamos nessas constantes alteraçóes nos campos político, cultural e, porque não dizer, também historiográficas, como um período de transformações na estrutura e na concepção de um poder imperial romano, que não apenas se manteve no Oriente, mas se apresentava então sob uma nova roupagem. Entretanto, compreendemos que o chamado fim do poder imperial romano no Ocidente não significou uma ruptura completa com as antigas tradiçóes romanas. Muito menos que esse acontecimento tivesse representado uma dissolução completa e definitiva das relações políticas e militares entre o Império Romano, então com sua capital em Constantinopla, e as populações ditas bárbaras, das regiões do Mediterrâneo. Diferente disso, procuramos pensar nesse período, com sugerido por Peter Brown, como um processo de transformaçóes tanto políticas 
quanto culturais, que não podem ou devem ser compreendidos apenas como um balizador que separa duas grandes eras historiográficas. Ao contrário, vemos nesse processo uma possibilidade temática de estudos, no qual é possível uma análise das relações políticas entre uma estrutura de poder imperial romana tardo-antiga e as regiões mediterrânicas não mais pertencentes às fronteiras imperiais em fins do século V.

Nessa perspectiva, não pretendemos realizar um estudo que trate desse período como um divisor de águas entre a antiguidade e o medievo a partir de um processo angustiante e dramático de derrotas romanas e de uma "civilização" que desaparece do mapa europeu a partir de incursóes de populações bárbaras em seus territórios e instituições. Também não pensamos numa distinção e distanciamento geográficos demarcados a priori, separando o que poderíamos chamar de sociedades ocidentais e orientais.

Diferente disto, pretendemos problematizar, a partir das narrativas de Jordanes e de Procópio de Cesareia, que tipo de relações, conflituosas ou diplomáticas, é possível de se perceber entre o Império Romano de tradição grega e os governos bárbaros de regiôes Mediterrânicas, em especial os godos na Península Itálica, durante as décadas que separam a deposição de Romulus Augustulus em 476 e o início das guerras de Justiniano, na década de 530.

\section{Documentos}

Os dois historiadores selecionados para este breve estudo se apresentam atualmente como fontes indispensáveis para uma reflexão e uma pesquisa historiográfica desse período. Primeiramente, tomaremos alguns trechos da obra Getica (De origine actibusque Getarum), de Jordanes, historiador do século VI, que pretendia ser uma compilação do que o historiador considerava serem os grandes feitos das populações godas “[...] desde o começo até nossos dias” (JORDANES, Getica, I). ${ }^{4}$ Nosso interesse nessas narrativas estão centradas em duas partes específicas da obra: na Segunda, onde Jordanes descreve a chegada dos godos em território romano no século IV, sua aliança como federados do Império nas lutas contra Átila e a tomada do poder por Odoacro; e na Terceira, dedicada ao período no qual os godos estiveram sob a liderança de Teodorico e posteriores vitórias de Justiniano e do general bizantino Belisário, já no século VI.

Já a História das Guerras, de Procópio de Cesareia, trata dos conflitos entre o governo imperial romano de Justiniano e as populaçôes persa, no oriente, vândala no norte da África e goda na Itália. A obra está dividida em oito volumes que descrevem em separado essas três grandes frentes de batalhas imperiais: dois deles dedicados à Guerra Persa, outros dois à Guerra Vândala, três à Guerra Gótica e um oitavo e último volume, no qual o historiador faz um apanhado geral das cerca de duas décadas de combates entre romanos e "bárbaros”. Para este estudo, dedicaremos especial atenção às narrativas da Guerra Gótica.

Alguns fatores explicam a escolha por uma análise da produção desses dois historiadores nessa pesquisa. Primeiramente, trata-se de dois nomes frequentemente utilizados pela historiografia para se referir às relaçôes do poder imperial com populações não romanas (ou bárbaras) justamente no período por nós recortado para esse estudo. Assim sendo, além de os encontrarmos dentro do recorte cronológico de nosso interesse, o estudo das obras citadas acima nos permite uma abordagem geográfica também pretendida aqui, qual seja, a das relações travadas entre o governo imperial romano e estruturas de poder não-romanas em regiões do Mediterrâneo tardo-antigo. 
Ademais, as obras selecionadas dos dois autores são obras de História, ou seja, foram produzidas tendo como modelo de escrita o mesmo gênero narrativo. Soma-se a estes o fato de que são livros com datas de publicação muito próximas, os anos 550, e na mesma cidade, Constantinopla. Entretanto, Jordanes e Procópio de Cesareia centram suas descrições em pontos distintos dessas relações entre o governo imperial e as populações “bárbaras”, o que torna o estudo aqui proposto mais complexo e diversificado em possibilidades de análises. Jordanes tem como centro de suas narrativas as populações godas, enquanto Procópio, na História das Guerras, escreve a mando de Justiniano, sendo uma narrativa construída para conservar a memória dos grandes feitos das tropas imperiais contra populações bárbaras. ${ }^{5}$

\section{Os relatos sobre o ano 476}

Primeiramente, tomemos as narrativas de Procópio de Cesareia. As descriçóes da Guerra Gótica tem como marco inicial a narrativa dos acontecimentos que conduziram à deposição de Romulus Augustulus e morte de seu pai Orestes. Esse é o ponto de partida para uma sequência que serviria ao historiador para explicar disputas subsequentes pelo poder na Itália que desencadeariam as guerras entre o império e os godos durante o governo de Justiniano.

A relação entre romanos e godos na Guerra Gótica é tratada por Procópio como conflituosa ainda no período em que o governo imperial se fazia presente na Itália. O tratamento dispensado pelo historiador a essas populaçôes, tratadas na obra como "bárbaros" (assim como todas as demais populações não romanas estabelecidas no Mediterrâneo) é carregado com significados pejorativos e de inferioridade em comparação com o mundo romano imperial. Além disso, a identificação das populações não romanas simplesmente como "bárbaras” diz não lidar com as características específicas de cada grupo com quem os romanos mantinham algum tipo de contato, fossem eles conflituosos ou pacíficos. Segundo Patrick Geary, "os imperialistas romanos achavam mais fácil lidar com os outros povos quando vistos como povos étnicos homogêneos, e não como tão complexos e fluidos quanto a população romana” (GEARY, 2005, p. 75).

A deposição de Romulus Augustulus e de seu pai, Orestes, do poder imperial na Itália foi narrada por Procópio como tendo início no aumento da entrada de elemento bárbaro não só na península, mas principalmente nas fileiras do exército romano no século V.

E na proporção que o elemento bárbaro se fortalecia entre eles, o prestígio dos soldados romanos imediatamente declinava, e sobre o nome de aliança, eles foram mais e mais tiranizados pelos intrusos e oprimidos por eles (PROCOPIUS, De Bello Gothico, V, i. 4).

Destacam-se nesse trecho os termos utilizados pelo historiador para se referir à forma como os bárbaros haviam penetrado no território e no exército romano. Para ele, os italianos foram tiranizados e oprimidos por uma população estrangeira invasora. As pesquisas sobre o período não indicam uma interpretação consensual na historiografia sobre a presença bárbara na Itália como uma invasão violenta. Walter Goffart, por exemplo, trabalha com a hipótese de que os godos não teriam invadido a Itália e tomado o poder pela força, mas, ao contrário, teriam ali se instalado por um longo processo de migrações e instalação desses grupos junto às províncias romanas. Além do mais, vale destacar que Goffart fez duras críticas aos relatos de Procópio sobre os acontecimentos 
de 476, colocando em xeque a 'credibilidade' das narrativas da História das Guerras sobre o tema (GOFFART, 1980, p. 630-666).

Na sequência, a Procópio afirma que, uma vez tendo penetrado entre os romanos, os bárbaros teriam alcançado o poder na Itália, através da figura de Odoacro:

E de fato eles ordenaram Orestes [pai de Romulus Agusutulus e regente do governo imperial no período] a dar-lhes a terça parte dela [da Itália], e como ele não iria, por meio algum, aceitar isso, eles imediatamente o mataram. Havia agora entre os romanos um certo homem chamado Odoacro, um dos guarda-costas do imperador e, naquele momento, ele concordou em conduzir seus comandados, na condição de que eles o conduzissem ao poder (PROCOPIUS, De Bello Gothico, V, i. 5-6).

Feito isso, Odoacro teria conquistado a submissão dos bárbaros e consolidado seu poder na Península por uma década: "E dando a terça parte da terra aos bárbaros, e assim ganhando mais firmemente sua submissão, ele [Odoacro] manteve o poder supremo de maneira segura por dez anos.” (PROCOPIUS, De Bello Gothico, V, i. 8).

A forma violenta pela qual os romanos teriam perdido o controle do poder imperial na Itália seria reforçado pelo historiador mais adiante na narrativa, no livro V da Guerra Gótica, quando Procópio reproduz uma carta de Justiniano aos francos, na intenção de construir uma aliança militar contra os godos:

Os Godos, tendo tomado pela violência a Itália, que é nossa, tem não apenas recusado absolutamente em devolvê-la, mas tendo cometido posteriormente atos de injustiça contra nós que não toleramos e ultrapassam todos os limites (PROCOPIUS, De Bello Gothico, V, v. 8).

Destacamos aqui que Justiniano teria se referido à Itália ainda como possessão imperial ("é nossa”). Soma-se a isto o fato de Procópio afirmar na citação anterior que Odoacro manteve o poder na península de maneira segura por dez anos. Esses elementos são exemplos que nos permitem questionar se, para Procópio de Cesareia e, em se tratando de uma narrativa oficial do governo de Justiniano, também para o imperador, seria justo pensar que o Império Romano teria caído ou deixado de existir no Ocidente em 476, como se consolidou na historiografia contemporânea desde Edward Gibbon no século XVIII? Essa imagem historiográfica não parece encontrar argumento nas narrativas de Procópio de Cesareia.

Assim como nos relatos da Guerra Gótica, Jordanes também interpreta a subida de Odoacro ao poder na Itália como o resultado de uma invasão estrangeira articulada e uma tomada do governo pela força e violência. Isso nos é narrado pelo historiador na Segunda Parte da Getica:

Mas, pouco tempo depois de ter sido nomeado imperador Augustulus em Ravena por seu pai Orestes, Odoacro, rei dos turcílingos, que teria com ele os esciros, os hérulos e outras tropas auxiliares de diferentes povos, invadiu a Itália e, após matar Orestes, expulsou do trono seu filho Augustulus e o condenou ao exílio na fortaleza de Luculus em Campânia (JORDANES, Getica, XLVI, 242).

Ressaltamos aqui que, diferentemente de Procópio, Jordanes se preocupa em buscar identificar as populações não romanas presentes no processo (turcílingos, esciros e hérulos), evitando 
a classificação generalizante de "bárbaro" a esses povos. Entretanto, Jordanes concorda com o historiador de Cesareia ao tratar da tomada do poder imperial na Itália como sendo executada por grupos de populações não romanas sob uma liderança também estrangeira, que se estabeleceu na Itália pelo assassinato do regente Orestes e imposição do exílio ao Imperador Romulus Augustulus. Portanto, seria uma conquista executada pela força e pela violência. Neste ponto, as narrativas da Getica se aproximam das narrativas da Guerra Gótica, apresentando uma imagem de conflitos e disputas pelo poder na Península italiana na segunda metade do século V.

No entanto, contrariando os relatos de Procópio, Jordanes não parece ter tido dúvidas de que a deposição de Romulus Augutulus teria representado o fim do Império Romano no Ocidente. Isso fica evidente na sequência da narração do historiador:

Desse modo, o Império Romano do Ocidente, que Otavianus Augustus, o primeiro dos Augusti, tinha começado a governar setecentos e nove anos após a fundação da cidade de Roma, chegou ao seu fim com esse Augustulus quinhentos e vinte e dois anos após o início do governo de seus predecessores no Império e, desde então, Roma e a Itália foram governadas por monarcas godos (JORDANES, Getica, XLVI, 242).

Jordanes deixa claro nessa passagem que a deposição de Romulus Augustulus teria significado o fim do Império na Itália e o início de governos não romanos na Península. É um relato que trata 476 como um momento de conflitos e disputas, culminando numa ruptura que representava o fim de um grande ciclo de sucessóes de imperadores romanos no governo da Itália que, a partir de então, se curvava ao poderio de governantes godos.

$\mathrm{Na}$ sequência dos acontecimentos, podemos perceber em Procópio que as relaçóes entre o Império e os novos governos no Mediterrâneo não haviam se rompido definitivamente. Procópio afirma que a vitória do rei godo Teodorico na Itália sobre Odoacro, concretizada em 493, contou não apenas com o auxílio do imperador bizantino Zenão, como teria sido sugerida pelo próprio autocrata em Constantinopla:

Mas o imperador Zenão, que sabia como levar vantagem em qualquer situação na qual ele se encontrasse, aconselhou Teodorico a ir à Itália, atacar Odoacro e ganhar para ele e para os godos os domínios do Ocidente (PROCOPIUS, De Bello Gothico, V, i, 10).

Tomemos novamente de empréstimo as narrativas de Jordanes. Na Getica também é possível observar a relação de sujeição do governo do godo Teodorico na Itália ao imperador Zenão, em Constantinopla. E, se Procópio fala que o próprio imperador havia sugerido a Teodorico a governar sobre "romanos e italianos", Jordanes relata ainda as benesses alcançadas pelo novo governante da Itália em relação ao Império Bizantino:

O imperador Zenão recebeu com alegria a notícia que Teodorico havia sido proclamado rei por seu povo e o recebeu na capital com as honras devidas e o colocou entre os principais da corte (JORDANES, Getica, LVII, 289).

Mais adiante, Jordanes deixa claro que a citada "alegria" pelo reinado de Teodorico tinha também o consentimento do imperador no exercício do poder do rei godo sobre o território italiano: 
E foi no terceiro ano após sua entrada na Itália que, com o consentimento do imperador Zenão, Teodorico se despiu da vestimenta de homem particular e assumiu o ilustre manto real que o identificava como rei dos godos e dos romanos (JORDANES, Getica, LVII, 295).

É possível perceber, nesses dois historiadores com objetivos de registros distintos, que a visão de uma Queda de Roma no Ocidente, resultando numa ruptura das relaçóes entre bárbaros no Mediterrâneo e o governo imperial em Constantinopla, pode ser questionada. E, sendo assim, seria também possível repensar a ideia das Guerras de Reconquista de Justiniano, uma vez que a autoridade romana ainda se fazia presente com o governo bárbaro de Teodorico na Itália? Vejamos.

\section{Uma revisão documental sobre as guerras de Justiniano}

A sucessão do poder político na Itália, após a morte de Teodorico, dá-se pela regência imediata de Amalasunta, mãe do sucessor Atalarico, então com apenas oito anos de idade. Procópio teceu elogiosas características ao trabalho de Amalasunta à frente dos godos:

Agora Amalasunta, como tutora de seu filho, administrava o governo, e ela provou ser dotada de sabedoria e atenção pela justiça no mais alto grau, exibindo em grande medida um temperamento masculino (PROCOPIUS, De Bello Gothico, V, ii, 3).

Entretanto, Amalasunta temia ser vítima de uma usurpação, o que colocaria sua própria vida em risco na Itália. Diante dessa ameaça, a regente goda não hesitou em buscar proteção junto ao imperador Justiniano, o que foi assim narrado por Procópio:

Enviando a Bizâncio, ela pergunta ao imperador Justiniano se era seu desejo que Amalasunta, a filha de Teodorico, se poderia ir até ele; pois ela desejava partir da Itália o mais rapidamente possível. E o imperador, satisfeito com a sugestão, ordenou a ela ir e enviou ordens que a melhor das casas em Epidamus deveria ser colocada em prontidão, com ordem que quando Amalasunta chegasse, ela devia se hospedar ali e passar o tempo que ela desejasse, podendo então dirigir-se a Bizâncio (PROCOPIUS, De Bello Gothico, V, ii, 23-24).

Não apenas o fato de Amalasunta ter se voltado à proteção imperial num momento de ameaça eminente, mas a aceitação por parte de Justiniano em auxiliá-la em seu governo na Itália nos mostra que, na percepção de Procópio, e certamente também do imperador, os acontecidos do ano 476 não teriam colocado um fim definitivo nas relações políticas entre Constantinopla e a Itália. E essa relação não se resumia simplesmente à proteção militar. Como dito acima, seria possível perceber, neste período, uma relação que estaria no nível de uma subordinação política, que se mantinha desde os governos de Teodorico e do imperador Zenão.

Em outra passagem, temendo ainda pela falta de lealdade de seu filho Atalarico e pela própria vida, ameaçada pelos godos, a governante regente buscou salvar-se mais uma vez através da proteção imperial: "Por essa razão, ela desejava entregar o poder dos godos e italianos ao imperador Justiniano, a fim de que ela mesma pudesse ser salva” (PROCOPIUS, De Bello Gothico, V, iii, 12). E, reafirmando mais adiante o desejo de Amalasunta, completa o historiador: "[...] mas secretamente ela concordou em colocar toda a Itália nas suas mãos [do imperador Justiniano]” (PROCOPIUS, De Bello Gothico, V, iii, 28). 
Os exemplos acima mostram que a vinculação entre os governos da Itália, tomada pelos ditos bárbaros, e Constantinopla continuava viva ainda em meados do século VI. Averil Cameron afirma que a relação entre alguns dentre os novos reinos da Europa Ocidental com o imperador se daria mesmo em termos de patronato (CAMERON, 1996, p. 43).

A proteção dispensada por Justiniano a Amalasunta não evitou que a regente fosse assassinada. Esse ponto é fundamental na narrativa de Procópio, pois esta seria a principal motivação do imperador para lançar contra a Itália suas tropas, comandadas pelo general Belisário:

Agora Pedro ${ }^{6}$ protestava abertamente a Teodato e a outro godo, que por causa dessa ação que tinha sido cometida por eles, haveria uma guerra sem trégua entre o imperador e eles (PROCOPIUS, De Bello Gothico, V, iv, 30).

A sequência do texto apresenta a deflagração da guerra entre as tropas imperiais e os godos, que teria lugar na Itália pelas duas décadas seguintes:

E o Imperador, ao saber o que tinha acontecido com Amalasunta, imediatamente entrou na guerra, estando no nono ano de seu reinado [535]. (PROCOPIUS, De Bello Gothico, V, v, 1)

Jordanes, por seu turno, trata dos acontecimentos pós 476 na Terceira Parte da Getica. Nela, o historiador relata o fim da vida do governante godo na Itália, Teodorico, e como este cuidou da transição do poder, visto que o sucessor ainda era uma criança:

Mas como Teodorico havia chegado à velhice e se dava conta de que deixaria em pouco tempo este mundo, convocou os condes godos e os mais notáveis de seu reino e proclamou Atalarico como rei, embora ainda fosse um menino que não havia chegado aos dez anos, filho de sua filha Amalasunta e órfão de seu pai Eutarico. Ordenou-os, como se tratava de um testamento pronunciado oralmente, que honrassem a seu rei, que estimassem ao Senado e ao povo de Roma, e que implorassem, depois do favor divino, o favor do imperador do Oriente (JORDANES, Getica, LIX, 304).

Percebe-se aqui não apenas uma relação de aproximação entre godos e romanos, mas também uma relação de subordinação de autoridades, na qual o reino godo se colocava, na visão do próprio Teodorico, como subordinado do poder imperial em Constantinopla. Apesar de ter afirmado que o ano 476 teria significado o fim do Império Romano no Ocidente, Jordanes não classifica as guerras de Justiniano, já no século VI, como tendo sido motivadas por um projeto de reconquista ou restauração das fronteiras imperiais no Mediterrâneo. Concordando com Procópio de Cesareia, Jordanes identifica o início das guerras contra os godos na Itália com o assassinato de Amalasunta, o que o imperador teria considerado uma afronta pessoal:

Quando Justiniano se inteirou disto [da morte de Amalasunta], se comoveu profundamente e considerou como uma afronta pessoal a morte de seus protegidos. Precisamente nesta época, havia conseguido uma grande vitória sobre os vândalos na África, graças a eficaz intervenção de seu muito leal patrício Belisário, e mandou a este mesmo general, que atacasse sem demora aos godos, quando suas armas ainda estavam empapadas de sangue dos vândalos (JORDANES, Getica, LX, 307). 
Portanto, o que vemos, tanto em Procópio quanto em Jordanes, é uma guerra que se inicia com Justiniano não com objetivos pré-estabelecidos de restaurar as antigas fronteiras imperiais no Ocidente, mas uma reação do governo de Constantinopla ao que considerava ser violação nas estruturas de poder estabelecidas na Itália, que mantinham, até então, o governo godo sob tutela e proteção do poder imperial ainda no século VI.

\section{Considerações finais}

Essa breve reflexão sobre as relações entre o poder imperial romano tardo-antigo, ou bizantino, e as autoridades godas na Itália, no período entre a chamada Queda do Império Romano do Ocidente, em 476, e o início da Guerra Gótica, em 535, não parecem ter sido sentidas pelos contemporâneos a partir do prisma do fim do poder romano no Mediterrâneo e um processo belicoso para a reconquista imperial em terras ocidentais.

Neste artigo, propusemos não pensar numa distinção entre Oriente e Ocidente, ou Antigo e Medieval. Pensamos numa possibilidade de analisar as relaçóes possíveis entre populações, governos e fronteiras distintas, não percebidas exclusivamente como conflituosas, mas verificando as possibilidades de aproximações e alianças politicamente fundamentas, envolvendo o Império Romano, então com sede de governo em Constantinopla, e uma população bárbara em específico, os godos, entre fins do século V e o início do VI. Trabalhar com dois autores com diferentes objetos e objetivos e, por isso mesmo, com perspectivas distintas de narrativa histórica certamente pode nos oferecer algumas consideraçôes consistentes para esta proposta.

No caso da História das Guerras, percebemos que seu autor, Procópio de Cesareia, não trata o ano de 476 como o fim definitivo do poder romano no ocidente. Consequentemente, também não o encontramos fundamentando as guerras de Justiniano como tendo o objetivo de "reconquista" ou de "restauração" de fronteiras imperiais no Mediterrâneo, como a historiografia mais tradicional consagra esse conflitos. Tais expressões sequer são encontradas na obra de Procópio.

A outra obra trabalhada aqui, a Getica, de Jordanes, não deixa dúvidas de que, para o autor, o ano 476 representou definitivamente o "Fim do Império Romano do Ocidente". Entretanto, ao tratar dos acontecimentos que se seguiram nas últimas décadas do século V, Jordanes também aponta a existência de uma relação de aliança entre o imperador bizantino Zenão e o novo governo godo de Teodorico. Também para Jordanes, as guerras de Justiniano não recebem o rótulo de guerras pela "reconquista" do Império no Ocidente, mas como uma resposta a uma tentativa de tomada do poder na Itália que colocava em risco a relação estabelecida entre romanos e godos nas primeiras décadas do século VI.

Outro ponto aproxima os dois historiadores. Tanto Procópio quanto Jordanes apontam para uma manutenção da relação de poder entre os governos bárbaros no Mediterrâneo e, neste caso, os godos na Itália, e a capital do Império Romano, em Constantinopla. Encontramos nas duas obras selecionadas as narrativas de um desejo e um esforço dos imperadores romanos em fazer sentir a presença de sua autoridade em espaços mediterrânicos, mesmo esses territórios não pertencendo mais às fronteiras do Império. Portanto, encontramos nas duas narrativas uma busca pela fundamentação do exercício de poder imperial, em termos de alianças e intervenções políticas e militares, num cenário de reorganização de novos espaços de poder em disputa, entre fins do século V e início do século VI. 
Dessa forma, ao propor este estudo, acreditamos que as imagens tradicionais da historiografia tardo-antiga, como a da Queda do Império Romano do Ocidente ou as Guerras de Reconquista de Justiniano, podem se apresentar como excessivamente simplistas e superficiais ao pesquisador. Ao nos debruçarmos sobre dois testemunhos do século VI, encontramos relações muito mais complexas e disputas pelos espaços de poder nas antigas possessões imperiais no Mediterrâneo.

Portanto, acreditamos que estas reflexões, embora pontuais, nos permitam relativizar imagens historiográficas tradicionalmente consagradas, repensar os usos dos documentos do período tardo -antigo para a compreensão das relaçóes entre o Império Romano oriental, ou Império Bizantino, e as populaçốes bárbaras do ocidente mediterrânico e, por fim, perceber que as divisões temáticas, sejam cronológicas ou geográficas, podem limitar a compreensão de processos de alianças ou disputas pelo exercício da autoridade que circulam por regióes e períodos que nem sempre coincidem com as grandes divisões temáticas propostas pela historiografia.

\section{Referências}

BROWN, Peter. The Later Roman Empire. The Economic History Review, v. 20, n. 2, p. 327-343, ago. 1967.

CAMERON, Averil. The Mediterranean World in Late Antiquity. A.D. Londres; Nova York: Routledge, 1996.

CAMERON, Averil. The Mediterranean World in Late Antiquity. A.D. Londres; Nova York: Routledge, 1996.

GEARY, Patrick. O mito das nações. A invenção do nacionalismo. Tradução Fábio Pinto. São Paulo: Conrad, 2005.

GIBBON, Edward. Declínio e queda do Império Romano. Tradução Maria Emília Ferros Moura. Lisboa: Difusão Cultural, 1995.GOFFART, Walter. Barbarians and Romans. A.D. 418-584. The techniques of accommodation. New Jersey: Princeton University Press, 1980.

GOFFART, Walter. Los Bárbaros en la Antigüedad Tardía y su Instalación en Occidente. In: LITTLE, Lester; ROSENWEIN, H. La Edad Media a debate. Tradução Carolina del Olmo e César Rendueles. Madri: Ediciones Akal, 2003. p. 50-79.

JORDANES. Getica. The Gothic History of Jordanes. In English version with a Introduction and a commentary. By Charles Christopher Mierow. Princeton: Princeton University Press; London: Humphrey Milford; Oxford University Press, 1915.

MARTIN, José Maria Sanchez (ed.). El autor: pefil biográfico de Jordanes. In: JORDANES. Origen y gestas de los godos. Tradução José Maria Sanchez Martin. Madrid: Ediciones Cátedra, 2001. p. 9-53.

PROCOPIUS. De Bello Persico (Uper Twn Polemon). History of The Wars. The Persian War. English translate by H. B. Dewing. London: Havard University Press, 1996. [1. ed. 1914].

PROCOPIUS. De Bello Gothico (Uper Twn Polemon). History of The Wars. The Gothic War. English translate by H. B. Dewing. London: Havard University Press, 2006.

\section{Notas}

\footnotetext{
${ }^{1}$ Adotamos aqui o conceito de Antiguidade Tardia, proposto por Peter Brown no livro The World of Late Antiquity: A.D. 150-750, publicado em 1971, para se referir ao período de transformações e continuidades verificados na Europa no período que engloba os últimos séculos de existência de um poder imperial romano no Ocidente latino e a formação de novos reinos bárbaros na Europa, nos primeiros séculos do que se convencionou chamar de Idade Média. Entretanto, não adentraremos aqui nos debates sobre rupturas ou continuidades do mundo antigo no início do período medieval. Para estas discussões, cf. BROWN, Peter. The Later Roman Empire. The Economic History Review, v. 20, n. 2, p. 327-343, ago. 1967. Para uma reavaliação dessa proposta, cf. CAMERON, Averil. The Mediterranean World in Late Antiquity. A.D. Londres; Nova York: Routledge, 1996.
} 
2 Preferimos chamar o Império historiograficamente conhecido como Bizantino como Romano para este período, pois entendemos que os contemporâneos dos eventos aqui tratados, incluindo aqui Jordanes e Procópio de Cesareia, compreendiam que essa estrutura política era romana, chamando essas populações de romanas, não de bizantinas. As referências ao termo Bizâncio nessas fontes tratam exclusivamente da capital Constantinopla, e não das fronteiras políticas imperiais como um todo. A referência ao termo Império Bizantino como algo diferenciado em relação à antiga Roma é uma construção historiográfica ocidental posterior, que encontra seus primeiros registros na Europa do século XVI.

${ }^{3}$ Em um a outra perspectiva historiográfica, esse período pode ser também abordado como Alta Idade Média.

${ }^{4}$ O Prólogo da obra de Jordanes se inicia com a apresentação do objetivo, imediatamente anterior ao trecho citado, de ser um resumo ou uma compilação com suas próprias palavras dos doze volumes da obra perdida do Senador Flávio Magno Aurélio Cassiodoro, sobre a origem e os grandes feitos dos godos. Por conta disso, há um longo debate entre os estudiosos de Jordanes, se este teria sido apenas um compilador da obra de Cassiodoro ou se é possível ver na Getica um certo grau de autonomia e originalidade do autor (MARTIN, 2011, p. 18-19).

${ }^{5}$ Procópio de Cesareia inicia a narrativa da Guerra Persa, o primeiro dos oito livros da História das Guerras, afirmando que sua narrativa deveria conservar a memória das guerras como grandes eventos, a fim de servirem como exemplo às gerações futuras, caso se encontrassem em situação semelhante: “Ele [Procópio] considera que a memória desses eventos seria uma grande coisa e muito útil para os homens, tanto do tempo presente quanto das gerações futuras, caso o tempo devesse colocar os homens sob uma tensão similar" (PROCOPIUS, De Bello Persico I. i, 1). É uma concepção de História que aproxima a escrita de Procópio daquela de Cícero, da obra De Oratore (século I a.C.), entendo a História como a magister vitae, "mestra da vida".

${ }^{6}$ Identificado como um cidadão de Tessalônica e orador retórico treinado, enviado pelo o Império Bizantino à Itália. Cf. PROCOPIUS, De Bello Gothico, V, iii, 30.

Data de recebimento: 30/11/2018

Data de aprovação: 20/05/2019 